\title{
Transatlantica
}

Revue d'études américaines. American Studies Journal

\section{Luc Benoit à la Guilllaume. Les discours d'investiture des présidents américains ou les paradoxes de l'éloge.} Paris : L'Harmattan, 2001. 304p.

\section{Larry Portis}

\section{OpenEdition}

\section{Journals}

Édition électronique

URL : http://journals.openedition.org/transatlantica/664

DOI : $10.4000 /$ transatlantica.664

ISSN : 1765-2766

Éditeur

AFEA

Référence électronique

Larry Portis, « Luc Benoit à la Guilllaume. Les discours d'investiture des présidents américains ou les paradoxes de l'éloge. », Transatlantica [En ligne], 1 | 2003, mis en ligne le 05 avril 2006, consulté le 29 avril 2021. URL : http://journals.openedition.org/transatlantica/664; DOI : https://doi.org/10.4000/ transatlantica.664

Ce document a été généré automatiquement le 29 avril 2021

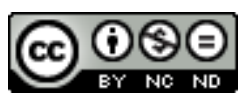

Transatlantica - Revue d'études américaines est mis à disposition selon les termes de la licence Creative Commons Attribution - Pas d'Utilisation Commerciale - Pas de Modification 4.0 International. 


\section{Luc Benoit à la Guilllaume. Les} discours d'investiture des présidents américains ou les paradoxes de l'éloge.

Paris : L'Harmattan, 2001. 304p.

\section{Larry Portis}

1 Étude universitaire des discours prononcés par les présidents américains à l'occasion de leur investiture, au cours du vingtième siècle, le travail de Luc Benoit, jeune américaniste, se distingue par un contenu théorique (concepts élaborés, intelligemment appliqués au sujet) et critique qui tranche sur la plupart des ouvrages universitaires. L'auteur ne borne pas son horizon à la connaissance des textes historiques et des ouvrages d'autres chercheurs dans le domaine qu'il traite. Les concepts empruntés à la théorie sociale ou sociologique critique et à la philosophie (à Marx, Terry Eagleton, Louis Althusser, Barbara Cassin, Pierre Bourdieu, entre autres) lui permettent d'élaborer sa propre grille de lecture. Comme il l'écrit dans sa conclusion: «Etudier les discours d'investiture, c'est poser la question de l'idéologie, au double sens de la critique des illusions, dans la tradition marxienne de la dénonciation de la fausse conscience, et de l'étude fonctionnelle de l'efficacité et du fondement institutionnel de ces illusions. Car ces discours sont l'objet d'une triple dénégation idéologique : celle de l'interdiscours, des conflits et de l'histoire » (287).

Par-delà l'apparente simplicité du sujet et la transparence des textes étudiés, l'objectif $\mathrm{du}$ livre est assez ambitieux. Il s'agit d'examiner comment une culture politique est soigneusement entretenue par une rhétorique destinée à renforcer l'idéologie dominante. D'où la possibilité pour l'auteur de se prononcer sur la nature même de l'idéologie : «[...] même si le consensus est l'une de ces illusions que l'Amérique « se fait sur elle", n'a-t-elle pas une influence sur les propos de ses dirigeants? Les mots ne sont pas que des outils rhétoriques qui représentent-ou trahissent-une réalité extérieure au discours, ils contribuent également à créer cette réalité » (289).

Malgré sa volonté de s'engager dans un débat aux implications politiques, L. Benoit ne manque pas de nuancer ses propos. S'expliquant sur sa méthode, il souligne, en faisant 
reférence à Mikhail Bakhtine: "Les discours d'investiture ne se contentent pas du rappel des mythes fondateurs. Par-delà leur apparence constative apparaît leur rôle performatif de création des valeurs. Le travail de fabrication du consensus dépend des circonstances politiques et du rapport de forces. Le problème n'est donc pas de savoir si les allocutions sont idéologiques ou pas, mais plutôt d'étudier leur caractère plus ou moins ouvertement dialogique et d'essayer de relier les variations formelles et génériques à l'évolution de la conjoncture » (99).

4 Ici se pose la question d'une possible ambivalence ou ambiguïté entre démarche universitaire et buts politiques. Quoi qu'il en soit, il s'accomplit dans ce livre un mariage assez rare entre, d'une part, l'analyse littéraire et linguistique et, de l'autre, l'étude de la civilisation. L'examen de l'évolution idéologique et des changements politiques à travers les discours présidentiels se fonde sur le commentaire de texte, exercice très prisé dans l'enseignement supérieur français. Or, l'auteur réussit à maitriser cette technique sans (comme c'est souvent le cas) s'y laisser enfermer. En effet, avec un tel sujet le grand danger est de se cantonner dans le descriptif ou dans l'analyse des mécanismes rhétoriques. Ces pièges sont heureusement évités et le résultat est de grande qualité.

Certes, l'ouvrage reste fortement marqué par son origine universitaire et conserve les caractéristiques d'une thèse, légèrement remaniée pour publication. Il est regrettable que l'éditeur n'ait pas introduit d'interligne entre le texte et les citations longues. Et que l'auteur n'ait pas traduit les très nombreuses citations: cela réduit le nombre potentiel de lecteurs. Mais ce ne sont là que critiques de forme, qui ne doivent décourager personne de lire un ouvrage qui est un excellent exemple de recherche en civilisation américaine.

INDEX

Thèmes : Recensions

\section{AUTEUR}

\section{LARRY PORTIS}

Université Paul-Valéry - Montpellier 3 